\title{
Aerosol characterisation of nebulised liposomes co-loaded with erlotinib and genistein using an abbreviated cascade impactor method
}

\author{
Nattika Nimmano $^{1}$, Satynarayana Somavarapu ${ }^{1} \&$ Kevin M.G Taylor $^{1}$ \\ ${ }^{1}$ UCL School of Pharmacy, 29-39 Brunswick Square, London, WC1N 1AX, United \\ Kingdom
}

Corresponding authors: Nattika Nimmano and Kevin Taylor, Department of Pharmaceutics, UCL School of Pharmacy, 29-39 Brunswick Square, London, WC1N 1AX, United Kingdom (n.nimmano@ucl.ac.uk and kevin.taylor@ucl.ac.uk)

\begin{abstract}
Erlotinib and genistein co-loaded liposomes were prepared by the thin-film hydration method. The effect of probe sonication as a size reduction method on drug incorporation and the properties of aerosols generated using air-jet and vibrating-mesh nebulisers was studied. The use of the Next Generation Impactor (NGI) to characterise inhaler formulations is limited by the need accurately to quantify drug deposited across 8 stages and is labour intensive to use. The Fast Screening Impactor (FSI) comprising two impaction stages was compared with the NGI to evaluate its applicability as a simple screening and labour-saving tool to characterise nebulised systems. For the developed liposomal formulations, an air-jet nebuliser generated a two-fold higher fine particle fraction (FPF) than a vibrating-mesh nebuliser. The findings demonstrated that the cooled FSI $\left(5^{\circ} \mathrm{C}\right)$ operated at $15 \mathrm{~L} / \mathrm{min}$ was effective in differentiating the aerosol properties of the nebulised liposome formulations investigated. Overall, the optimised co-loaded liposomes were more effectively delivered by an air-jet nebuliser, than from a vibrating-mesh nebuliser over a 10 minute period as determined using the abbreviated impactor.
\end{abstract}

Keywords: erlotinib; genistein; probe-sonication; impactor; nebuliser

\section{Introduction}

Genistein and erlotinib, hydrophobic drugs of BCS class II, are characterised by low aqueous solubility and high permeability. Combination treatment with these drugs has shown synergistic activity with epidermal growth factor receptor-tyrosine kinase inhibitors (EGFR-TKIs) in three separate non-small cell lung cancer (NSCLC) cell 
lines; H3255, H1650 and H1781(Gadgeel et al., 2009). Genistein and erlotinib represent a rational and challenging combination for co-delivery directly to the airways in an appropriate delivery system for local treatment of NSCLC. Liposomes have been investigated for pulmonary delivery, incorporating a wide range of hydrophilic and hydrophobic therapeutic agents, including those for cancer treatment (Elhissi et al., 2011; Rudokas et al., 2016; Sercombe et al., 2015). They are considered safe, selfassembled, biocompatible and biodegradable lipid-based nanocarriers, particularly suitable for pulmonary delivery due to their size, the presence of endogeneous mechanisms in the lung for clearance of phospholipid and their ability to release drug in a sustained manner and interact with airway's cells via a number of mechanisms (Elhissi et al., 2011; Rudokas et al., 2016; Sercombe et al., 2015). Moreover, liposomes can also be engineered to also enhance the targeting efficiency and cellular uptake through selection of particular size fractions or by modification of liposomal surface; for example, macrophage-specific ligands and chitosan coating to enhance internalisation and limit toxicity of rifampicin-loaded liposomes (Manca et al., 2012; Vyas et al, 2004).

Nebulisers have advantages, compared to pressurised metered-dose inhalers (pMDIs) and dry powder inhalers (DPIs) of delivering large doses/dose volumes, requiring minimal processing (e.g. lack of organic solvents and drying stages) and the capability of delivering drugs during normal tidal breathing. Air-jet and vibrating-mesh nebulisers has been previously reported to be most appropriate to generate stable liposomal aerosols from aqueous dispersions, rather than ultrasonic devices. During aerosol generation, ultrasonic nebulisers generate high frequency waves in the fluid being nebulised generating and heat that may degrade liposomes resulting in fusion and drug loss, whereas air-jet and vibrating-mesh devices are less disruptive of the lipid bilayers (Elhissi et al., 2012; Elhissi et al., 2013). Air-jet nebulisers may lead to significant loss of entrapped hydrophilic drug, due to shearing forces within the nebuliser (Bridges and

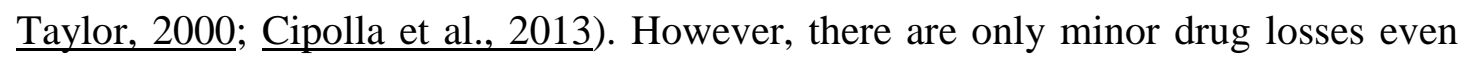
with vesicle disruption during nebulisation for hydrophobic drugs since most of lipophilic drugs are still entrapped within the liposomal bilayer (Cipolla et al., 2013; Elhissi et al., 2011; Elhissi et al., 2013). Furthermore, the destabilising forces within such devices had shown no significant impact on particle aggregation and drug leakage when the physical stability of liposomes with respect to size of deposited liposomes 
across the different stages of the Next Generation Impactor (NGI) (Manca et al., 2015). Vibrating-mesh nebulisers, which extrude liquid through a perforated mesh to generate aerosols, have been reported to cause less damage to liposomes than other nebulisation methods, minimizing hydrophilic drug losses. They are thus are considered highly suitable for liposome delivery (Elhissi et al., 2012; Elhissi et al., 2013; Elhissi et al., 2006a).

The European Pharmacopoeia (Ph. Eur. 9.0, 2017) describes the use of the Next Generation Impactor (NGI; Apparatus E) for determining the aerosol particle size distribution of nebulised aerosols. The Glass/Two-Stage Impinger (TSI; Apparatus A) is also described and has limited application for characterising nebulised aerosols. The TSI, a simple cascade impactor, has a number of disadvantages, in particular, the cutoff diameter for stage $2 /$ lower stage is $6.4 \mu \mathrm{m}$, rather than $5 \mu \mathrm{m}$, as recommended for calculating the fine particle dose (FPD) (EMA guideline, 2006; Ph. Eur. 9.0, 2017) and fine particle fraction (FPF). Also, the high flow rate employed $(60 \mathrm{~L} / \mathrm{min}$ for nebulisers) may result in rapid solvent evaporation, leading to a significant decrease in measured aerosolised size. The NGI was originally introduced for the determination of the aerodynamic particle size distribution of the emitted dose generated by pMDIs and DPIs using the flow rate range of $30-100 \mathrm{~L} / \mathrm{min}$. According to the Ph. Eur., for nebulised systems cooling of the NGI is required at $5^{\circ} \mathrm{C}$ for at least $90 \mathrm{~min}$ before use to prevent evaporation effects and to limit the change in droplet size during the testing. The calibrated impactor is used at a flow rate of $15 \mathrm{~L} / \mathrm{min}$ with a filter after the Micro-Orifice Collector (MOC) to retain the extra-fine particles from small aerosol droplets (Abdelrahim, 2011; Berg et al., 2007; Zhou et al., 2005). However, aerosolised drug is deposited over the eight stages of the NGI, which causes analytical quantification challenges for formulations with potent drugs at low concentration.

Abbreviated Impactor Measurement (AIM) is a concept employing a two- or threestage impactor, often an abbreviated version of multistage NGI or Andersen cascade impactors, which has been proposed and is being investigated as rapid technique for quality control of inhalation products. AIM utilises only impactor stages collecting coarse and fine aerosol fractions (two-stages) and occasionally also an extra-fine particle fraction (three-stages) (Mitchell et al., 2009; Mohan et al., 2017). This allows a more rapid analysis and more accurate quantification at low drug concentrations, 
though less information is available than from a full impactor regarding the distribution of sizes within the aerosol cloud, and parameters useful in pharmaceutical development such as mass median aerodynamic diameter (MMAD) cannot be calculated. The Fast Screening Impactor (FSI), which is not yet included in European, United States or Japanese Pharmacopoeias, is a two-stage abbreviated impactor, with a cut off diameter between stages of $5 \mu \mathrm{m}$. The FSI has been demonstrated as a quick and simple technique for the in-vitro determination of FPD for DPIs and pMDIs, yielding comparable figures for this key metric to those derived using extended impactors (ElGendy et al., 2012; Guo et al., 2013; Mohan et al., 2017). However, the use of the FSI for determining the properties of nebulised formulations has not been investigated widely.

In this study the means of aerosolisation (air-jet and vibrating-mesh nebulisers) and properties of co-loaded genistein and erlotinib liposomes, size reduced by probe sonication, were investigated, with aerosol characterisation conducted using both the FSI and NGI. The aim of this work is to investigate the potential of a co-loaded liposomal system for nebuliser delivery, using the FSI to overcome analytical quantification problems resulting from use of nanocarriers with low drug content.

\section{Materials and methods}

\subsection{Materials}

Erlotinib 99\% and genistein (4',5,7-trihydroxyisoflavone) (LC Laboratories, USA) were used as hydrophobic drugs. The phospholipids, DPPC (1,2- dipalmitoyl- sn-

glycerol- 3- phosphocholine) and DOPE (1,2-dioleyl- sn- glycerol- 3phosphoethanolemine) supplied by Lipoid (Ludwigshafen, Germany) were used without further purification as the major and helper lipids, respectively. Cholesterol (Sigma-Aldrich; Poole, UK) was used as the bilayer stabiliser in the formulation. Absolute ethanol, chloroform (99.8\%, analytical grade) and HPLC grade water were obtained from Sigma-Aldrich (Poole, UK). For HPLC analysis, the following reagents and solvents were acquired from Sigma-Aldrich (Poole, UK): dimethyl sulfoxide (DMSO, >99.7\%, HPLC gradient grade), acetonitrile (99.9\%, HPLC gradient grade), and trifluoroacetic acid (TFA, >99.0\%).

2.2 Preparation of erlotinib and genistein co-loaded liposomes 
Multilamellar vesicles (MLVs) were prepared by the lipid thin-film hydration method. The phospholipid phase comprising DPPC (72\% mol), cholesterol $(8 \% \mathrm{~mol})$ and DOPE (20\% mol) and erlotinib and genistein $(2.50 \% \mathrm{w} / \mathrm{w}$ each drug in total lipid) were dissolved in a mixture of absolute ethanol and chloroform $(4: 1 \mathrm{v} / \mathrm{v})$ in a round-bottomed flask. The solvent was removed using a rotary vacuum evaporator ( $\mathrm{RC} 900, \mathrm{Knf}$ Neuberger $\mathrm{GmbH}$, Germany) under reduced pressure at $60^{\circ} \mathrm{C}$ for 20 min to obtain a thin film of drug/lipid. The dry thin film was flushed with nitrogen gas to remove residual solvent and then hydrated with $20 \mathrm{~mL}$ of HPLC water by vigorous handshaking, followed by gentle rotation at $60^{\circ} \mathrm{C}$ for $30 \mathrm{~min}$ at $200 \mathrm{rpm}$ in a water bath to produce MLVs containing total drug concentration of $1.0 \mathrm{mg} / \mathrm{mL}(0.5 \mathrm{mg} / \mathrm{mL}$ each of both drugs) at a final phospholipid concentration of $20 \mathrm{mg} / \mathrm{mL}$.

The size of the resultant MLVs was reduced by probe-sonication to achieve the required mean size. Briefly, $20 \mathrm{~mL}$ of MLVs were placed in a $20 \mathrm{~mL}$ glass vial and kept in an ice bath throughout the experiment. Probe sonication (MSE Soniprep 150, MSE, UK) was performed at 12 watts constant output for $30 \mathrm{~min}(5 \mathrm{~min} /$ cycle and $1 \mathrm{~min}$ cooling at $4^{\circ} \mathrm{C}$, to avoid overheating). The titanium probe (9.5 mm diameter) was immersed to a depth of $15 \mathrm{~mm}$ above the bottom of the glass vial. The time for sonication was optimised to obtain a mean diameter of 100 to $200 \mathrm{~nm}$ (Kannan et al., 2015).

Non-incorporated drug was separated by syringe filtration, $2 \mathrm{~mL}$ of formulations was filtered through a $0.45-\mu \mathrm{m}$ cellulose acetate membrane filter (Merck Millipore Ltd.,

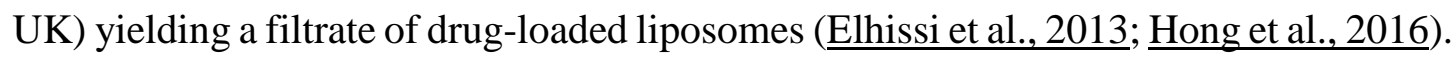

\subsection{Characterisation of co-loaded liposomes}

\subsubsection{Determination of particle size distribution and zeta potential}

Particle size distribution and zeta potential of liposomes were measured using the Malvern Nano ZS Zetasizer (Malvern Instruments Ltd, UK). $1.0 \mathrm{~mL}$ of liposomes was placed undiluted into the zeta potential DTS1070 folded capillary cell (Malvern, UK) and properties measured at $25^{\circ} \mathrm{C}$. The hydrodynamic diameter (expressed as Z-average value) and the size distribution (polydispersity index, PDI) were determined by dynamic light scattering (DLS). A PDI $<0.1$ is typically considered as representing a monodispersed system, $<0.3$ is a relatively monodisperse system, while $>0.7$ is 
classified as a polydispersed system ( $\underline{\text { Holmkvist et al., 2016}}$ ISO-22412, 2008; Kannan et al., 2015).

Zeta potential was measured based on electrophoretic mobility using the HelmholtzSmoluchowski equation. Three independent measurements were performed and data are expressed as mean values.

\subsubsection{Determination of drug loading and encapsulation efficiency}

A validated analytical method was developed for simultaneous quantification of erlotinib and genistein to allow calculation of entrapment efficiency and drug loading. The analysis was carried out using a high performance liquid chromatography (HPLC) system equipped with an auto sampler and UV/Vis detector (Agilent 1100 Series, USA) at wavelength $246 \mathrm{~nm}$ for quantification of erlotinib and $260 \mathrm{~nm}$ for genistein. A Synergi Polar-RP $80^{\circ} \mathrm{A}$ HPLC Column $(250 \times 4.6 \mathrm{~mm} \times 4 \mu \mathrm{m})$ was used as the stationary phase for separation. Isocratic elution was carried out with a mobile phase comprising a mixture of $100 \% \mathrm{v} / \mathrm{v}$ acetonitrile and $0.1 \% \mathrm{v} / \mathrm{v}$ TFA in HPLC grade water $(50: 50 \% \mathrm{v} / \mathrm{v})$. The eluents were degassed before pumping through the column at a flow rate of $1 \mathrm{~mL} / \mathrm{min}$. The column temperature was $25^{\circ} \mathrm{C}$ and the sample injection volume was $10 \mu \mathrm{L}$, with a run time of $10 \mathrm{~min}$. The UV wavelength was set to shift from 246 $\mathrm{nm}$ to $260 \mathrm{~nm}$ after $5.2 \mathrm{~min}$. The method was validated for linearity, precision, accuracy, limit of detection and limit of quantification for intra- and inter-day following the ICH Q2 guideline ( $\mathrm{ICH}$ Guideline, 2005). $1 \mathrm{~mL}$ of formulation was diluted with ethanol to a final volume of $5 \mathrm{~mL}$ prior to HPLC analysis. The entrapment efficiency $(\% \mathrm{EE})$ and drug loading (\%DL) were calculated using the following equations:

Drug loading $(\% D L)=\frac{\text { Mass of drug in liposomes }}{\text { Mass of phospholipid and drug }} \times 100 \%$

Entrapmet Efficiency $(\% E E)=\frac{\text { Mass of drug in liposomes }}{\text { Mass of drug for encapsulation }} \times 100 \%$

\subsubsection{Differential Scanning Calorimetry (DSC)}

High Sensitivity Differential Scanning Calorimeter (HSDSC) was conducted using a Multi cell DSC (TA instruments, Newcastle, UK). Sonicated liposome dispersions (1 $\mathrm{mL}$ ) having lipid concentration of $40 \mathrm{mg} / \mathrm{mL}$ were placed into a DSC sample cell (TA 
Instruments, Newcastle, UK) which was sealed using a rubber O-ring and cell cap to ensure an airtight fit. The reference cell was empty. Nitrogen was supplied to prevent vapour condensation on the sample cells during the cooling process (Elhissi et al., $\underline{2006 \mathrm{~b}}$; Saunders et al., 2007). All scans were undertaken at a scan rate of $0.5^{\circ} \mathrm{C} / \mathrm{min}$ from 15 to $70^{\circ} \mathrm{C}$. The thermal behaviour of liposomes was evaluated based on the temperature of the pre-transition $\left(\mathrm{T}_{\mathrm{pre}}\right)$, main phase transition temperature $\left(\mathrm{T}_{\mathrm{m}}\right)$, enthalpy $(\Delta \mathrm{H})$ and half height width (HHW) of the main endothermic peak using the instrument software. Three independent DSC measurements were determined and are reported as mean value $\pm \mathrm{SD}$.

\subsection{Aerosol characterisation of nebulised liposomes}

\subsubsection{Assessment of aerosol properties using the Next Generation Impactor (NGI)}

The NGI (Copley Scientific, UK) was set up according to the requirements of the Ph. Eur., after cooling the impactor at $5^{\circ} \mathrm{C}$ for at least $90 \mathrm{~min}$ to minimise solvent evaporation during use (Abdelrahim, 2011; Berg et al., 2007; Manunta et al., 2011). The air-jet nebuliser with mouthpiece (Pari LC® Sprint Reusable nebuliser, PARI Medical Ltd, Byfleet, UK) was directed towards the induction port with a mouthpiece adapter, and the NGI was attached to the vacuum source (Copley Scientific, UK). The compressor (Pari TurboBoy, PARI Medical Ltd, Byfleet, UK) generated the medium air-flow rate of 4.0-6.0 L/min through the nebuliser chamber (Dennis et al., 2008; Kendrick et al., 1997), whereas the air being drawn through the NGI was monitored by flow meters (Copley Scientific, UK) at $15 \mathrm{~L} / \mathrm{min}$, which represents the midpoint of adult tidal breathing using a nebuliser (Berg et al., 2007; Chan et al., 2011; Manunta et al., 2011). $4 \mathrm{~mL}$ of optimised liposomal suspension (containing $0.8 \mathrm{mg} / \mathrm{mL}$ erlotinib and $10 \mathrm{mg} / \mathrm{mL}$ genistein, based on the entrapment-efficiency levels) was added into the jet nebuliser reservoir and nebulisation continued for $10 \mathrm{~min}$. Nebulised liposomes were collected by rinsing with absolute ethanol from the nebuliser reservoir, induction port, NGI collection cups and the $7 \mathrm{~mm}$ diameter glass microfiber filter (Whatman®, UK) at the end of the experiment. A back-up filter, recommended by previous studies, was placed after the Micro Orifice Collector (MOC, which is the final stage in the NGI), to retain the smallest aerosol droplets when the NGI is operated at $15 \mathrm{~L} / \mathrm{min}$ (Abdelrahim, 2011; Berg et al., 2007). All collected samples were made up to fixed volumes for 
HPLC assay. The amounts of erlotinib and genistein deposited on the induction port, all NGI stages, internal filter and that remaining in the nebuliser were quantified by HPLC analysis. The limits of quantification and detection for HPLC analysis were 3.00 and $0.34 \mu \mathrm{g} / \mathrm{mL}$ for erlotinib and 2.00 and $0.25 \mu \mathrm{g} / \mathrm{mL}$ for genistein, respectively.

2.4.2 Assessment of aerosol properties using the Fast Screening Impactor (FSI)

The FSI was investigated as an alternative to the NGI for aerosol characterisation of nebulised liposomes under the same operating conditions. Further study of the effect of air-flow rates, impactor temperatures and nebuliser systems on measurements were also conducted (Sections 2.4.2.1 to 2.4.2.3). Nebulisation of $4 \mathrm{~mL}$ of optimised liposomal formulation into the cooled FSI, via the induction port, was undertaken for 10 min using a flow rate of $15 \mathrm{~L} / \mathrm{min}$. After nebulisation was completed, the FSI was dismantled and erlotinib and genistein were recovered from the nebuliser reservoir, mouthpiece, mouthpiece adaptor, induction port, FSI housing containing additional insert and glass microfiber filter using appropriate volumes of absolute ethanol (Guo et al., 2013). All collected samples were then assayed by HPLC.

Thus, aerosolisation parameters for the NGI and FSI determined in this study were calculated as follows:

$\%$ Fraction recovered $\left(\%\right.$ FR)or $\%$ Mass balance $=\frac{\text { Mass of drug from nebulizer to filter }}{\text { Mass of drug initially placed into the nebuliser }} \times 100 \%$
$\%$ Emitted dose $(\%$ ED $)=\frac{\text { Mass of drug from induction port to filter }}{\text { Mass of drug from nebuliser to filter }} \times 100 \%$

Fine Particle Dose (FPD) for FSI = Drug mass from lower stage of the FSI

Fine Particle Dose (FPD) for NGI = Drug mass below $5 \mu \mathrm{m}$ from the plot of cumulative mass of active substance versus cut-off diameter in a log scale format

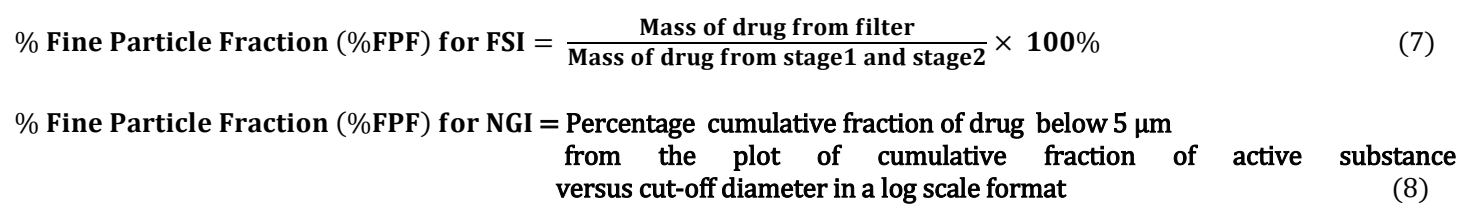

2.4.2.1 Effect of air-flow rate on measured aerosol properties 
The FSI used to characterise the nebulised aerosols had an additional insert (Copley Instruments, UK) calibrated at $30 \mathrm{~L} / \mathrm{min}$ to give a cut-off for aerodynamic diameter of $5 \mu \mathrm{m}$. When using the instrument with a flow rate of $15 \mathrm{~L} / \mathrm{min}$, this insert was modified by covering alternately three of the six nozzles with wet glass microfibre filter. The allowed retention of the stage cut-off diameter of $5 \mu \mathrm{m}$ at $15 \mathrm{~L} / \mathrm{min}$ (Tservistas et al., 2010), permitting determination of Fine Particle Fraction (FPF) and Fine Particle Dose

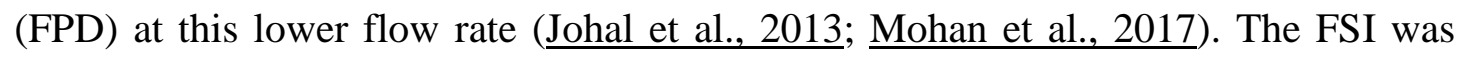
cooled at $5^{\circ} \mathrm{C}$ for at least 90 min before each individual determination.

\subsubsection{Effect of impactor temperature on measured aerosol properties}

The FSI was routinely cooled at $5^{\circ} \mathrm{C}$ for at least $90 \mathrm{~min}$ before using as this is recommended in the Ph. Eur. for the NGI. Experiments were also conducted with a non-cooled FSI (at ambient temperature; $20^{\circ} \mathrm{C}$ ). In this study, the impactor was operated at ambient and cooled conditions to determine the properties of nebulised liposomal formulations at both flow rates $(15 \mathrm{~L} / \mathrm{min}$ and $30 \mathrm{~L} / \mathrm{min})$.

\subsubsection{Effect of nebuliser system on measured aerosol properties}

Liposomal aerosols nebulised using an air-jet nebuliser (Pari LC®) Sprint, PARI Medical Ltd, Byfleet, UK) and vibrating-mesh nebuliser (Pari Velox®, PARI Medical Ltd, Byfleet, UK) with generated aerosols directed into the induction port of the FSI using a mouthpiece adaptor. The FSI was operated at air-flow rates of $15 \mathrm{~L} / \mathrm{min}$ and 30 $\mathrm{L} / \mathrm{min}$ at ambient temperature $\left(20^{\circ} \mathrm{C}\right)$ and after cooling the impactor at $5^{\circ} \mathrm{C}$ for at least 90 min.

\subsubsection{Stability of nebulised liposome before and after nebulisation}

Nebulisers and FSI stages were rinsed with $1 \mathrm{~mL}$ of HPLC grade water for particle size analysis after aerosol generation. The Z-average mean hydrodynamic diameter and Polydispersity Index (PDI) of formulations before and after nebulisation were measured in triplicate by DLS, together with transmission electron microscopy, to determine the effects of the type of nebulisers on liposome physical stability. The mean values and standard deviation from three time measurements were obtained. 


\subsubsection{Transmission Electron Microscopy (TEM) of liposomes}

The morphology and aggregation behaviour of co-loaded liposomes were observed using a transmission electron microscope (Philips Electron Optics BV, Netherlands). To prepare the samples for TEM, a drop of liposomes was placed on a copper grid and the excess fluid removed with filter paper. The sample was negatively stained with a drop of uranyl acetate $(1 \%, \mathrm{w} / \mathrm{v})$ and left in place for $2 \mathrm{~min}$. The sample was then dried under ambient conditions prior to loading into the TEM and viewing (Hadian et al., $\underline{2014 b} ; \underline{\text { Xie et al., 2012) }}$

\subsection{Statistical analysis}

All experiments were carried out in triplicate and results are expressed as the mean \pm standard deviation (SD). Data were statistically analysed using either Student's t-test or analysis of variance (ANOVA) and Tukey's post hoc test, using IBM SPSS Statistic 22 software. A $p$ value $<0.05$ was considered significant.

\section{Results and discussion}

\subsection{Size distribution and zeta potential of liposomes}

The size reduction of erlotinib and genistein co-loaded liposomes comprising DPPC, cholesterol and DOPE (72:8:20 mole\%) was optimised using probe-sonication. The duration of sonication was based on the encapsulation efficiency of erlotinib and genistein; with $30 \mathrm{~min}$ sonication required to achieve the desired encapsulation efficiency of both drugs, with a final mean diameter of approximately $200 \mathrm{~nm}$ after separating non-incorporated drugs by filtration. The mean size less than $200 \mathrm{~nm}$ demonstrates an efficiently passive tumour targeting ability through the enhanced permeability and retention (EPR) effect, resulting in the effectiveness of lung cancer treatment (Hassanzadeh et al., 2017; Mahajan and Mahajan, 2016). Furthermore, the smaller particle size of nanocarriers ensures efficient incorporation into droplets during aerosol generation (Amini et al., 2014; Dandekar et al., 2010).

The mean size of sonicated liposomes was significantly reduced after passing through the syringe filter (Table $1 ; \mathrm{p}<0.05$ ). The mean particle size before and after passing 
sonicated liposomes through the cellulose acetate filters was considerably smaller than the nominal pore size of $0.45 \mu \mathrm{m}$ cellulose acetate filters. The particle size distribution for sonicated liposomes was poydispersed, with DLS data showing multiple peaks in the frequency-size curves for pre-filtered formulations, possibly indicating the presence of free drug. However, the frequency-size curves for filtered sonicated liposomes showed only a single peak indicating the suitability of the method for removing unentrapped, insoluble drug as described previously (Elhissi et al., 2013; Hong et al., 2016). The mean measured surface charge as shown in Table 1 for all liposome preparations was not significantly different $(\mathrm{p}>0.05)$, the value being approximately neutral as expected based on the individual lipid components.

\subsection{Entrapment efficiency of erlotinib and genistein in liposomes}

The liposomal system was optimised to co-deliver erlotinib $(\log \mathrm{P}=2.69)$ and genistein $(\log \mathrm{P}=2.84)$. A previous study demonstrated that the incorporation of cholesterol and DOPE into liposomes of the saturated lipid hydrogenated soybean phosphatidylcholine (HSPC) at the appropriate ratio, changed the lipid packing and fluidity of the phospholipid bilayer, resulting in improvements in the entrapment efficiency and stability of genistein-containing liposomes as compared to HSPC liposomes (Phan et al., 2013). HSPC and cholesterol have also been used in the preparation of erlotinibloaded nanocarriers ( $\mathrm{Li}$ et al., 2017; Mandal et al., 2016). However, the coincorporation of erlotinib and genistein into liposomes has not previously been reported. In this study, DPPC was chosen as the main phospholipid component as it is a major component of pulmonary surfactant. The optimal ratio of DPPC and two drugs was fixed, and then cholesterol and DOPE content was optimised (as mole ratio) to obtain the optimal entrapment efficiencies and mean size. There were no significant differences ( $p>0.05$; data not shown) in entrapment efficiencies for both drugs between individual and co-loaded formulations comprising DPPC, cholesterol and DOPE (mole ratio of 72:8:20), yielding the entrapment efficiency of genistein and erlotinib of approximately $100 \%$ and $8.6 \%$, respectively (Table 1 ). Thus, the co-delivery of this combination was considered appropriate for further study. The significant difference in drug entrapment between these two drugs, may result from their chemical structures as discussed in Section 3.3. 
Previous research has demonstrated that the incorporations of hydrophobic steroids into sonicated liposomes was largely dependent on lipid composition (Elhissi et al., 2013). From Table 1, the total content of erlotinib and genistein including free drugs and drugloaded liposomes for pre-filtered MLVs after 30 min probe-sonication compared with initial weight of drug in liposome preparation was 100\%, indicating no drug loss during sonication before removing non-incorporated drugs by filtration. The entrapment efficiencies determined after separating non-incorporated drugs by passing through $0.45 \mu \mathrm{m}$ cellulose acetate membrane filters did not differ for genistein ( $p>0.05)$, though a significant difference was found for erlotinib $(\mathrm{p}<0.05)$. Thus, optimization of drug loading for this combination was not only dependent on the lipid composition but also on the physicochemical properties of the drugs (Eckert et al., 2011; Hadian et al., 2014; Rasti et al., 2012).

Overall, DPPC, cholesterol and DOPE in the mole ratio of 72:8:20\%, prepared by thinfilm hydration and sonication represented the best manufacturing and formulation approach in terms of particle size distribution and co-loading of drugs.

\subsection{Differential Scanning Calorimetry (DSC)}

DSC, a thermal analytical technique, has been used extensively to study liposomal systems, giving information on drug-liposome interactions which may impact entrapment efficiency, stability and drug release (Chen et al., 2014; Demetzos, 2008).

DSC thermograms showed that erlotinib and genistein co-loaded into DPPC liposomes produced a significant decrease $(\mathrm{p}<0.05)$ in the main phospholipid transition temperature $\left(\mathrm{T}_{\mathrm{m}}\right)$ from 42.7 to $41.3^{\circ} \mathrm{C}$ (Table 2). For drug-loaded DPPC liposomes, the $\mathrm{T}_{\mathrm{m}}$ of genistein-loaded DPPC liposomes decreased significantly $(\mathrm{p}<0.05)$ to $41.6^{\circ} \mathrm{C}$, while there was no significant change $(p>0.05)$ in $T_{m}$ for erlotinib-loaded DPPC liposomes. The inclusion of cholesterol and DOPE into DPPC bilayers also affected $\mathrm{T}_{\mathrm{m}}$. The presence of $8 \%$ mole of cholesterol, with and without $20 \%$ mole DOPE in erlotinib and genistein co-loaded DPPC liposomes, resulted in liposomes with considerably lowered $\mathrm{T}_{\mathrm{m}}(\mathrm{p}<0.05)$. The main phase transition represents the transition of the liposomal bilayer from the gel to liquid crystalline phase (Zhao et al., 2007). A decrease in the main transition indicated incorporation of the hydrophobic drugs into the hydrophobic hydrocarbon chain region of the bilayers, resulting in greater bilayer 
fluidity with increased rotational freedom of the phospholipid acyl chains. All formulations presented in Table 2 showed elimination of the pre-transition peak of empty DPPC liposomes at $39.36^{\circ} \mathrm{C}$, except for erlotinib-loaded DPPC liposomes. The pre-transition peak is particularly sensitive to the presence of molecules in the polar region of lipid bilayer (Taylor and Morris, 1995). The absence of this peak after either drug or lipid incorporation suggests some change in the orientation of the polar head groups of DPPC from one dimensional lamellar (Planar Gel Phase, $\mathrm{L}_{\beta^{\prime}}$ ) to a two dimensional monoclinic lattice (Rippled Gel Phase, $\mathrm{P}_{\beta^{\prime}}$ ) and indicates an interaction between the exogenous compound(s), including cholesterol, and the polar head group of lipids (Budai et al., 2003; Manca et al., 2013). However, the small pre-transition peak was still detected for erlotinib-loaded DPPC liposomes at $39.21^{\circ} \mathrm{C}$. Considering the chemical structures of the two drugs, nitrogen atoms from the quinazolinamine ring and oxygen from methoxyethoxy chains of the erlotinib molecule may form weaker ionic bonding with the phosphate and/or amine group of DPPC molecules, while three hydroxyl groups on the benzene rings of genistein molecule are easier to protonate and have a stronger ionic interaction with polar head group of DPPC. Erlotinib alone seems to have less impact on the phospholipid hydrocarbon chain region, determined by the change in $\mathrm{T}_{\mathrm{m}}$ compared with genistein and/or co-loaded DPPC liposomes. These observations suggest that genistein can penetrate deeper than erlotinib into the bilayer, with greater impact on the motion of the hydrocarbon region (Beni et al., 2006). This is also reflected in the significantly lower entrapment efficiency for erlotinib compared with genistein (Table 1). Inclusion of $8 \%$ mole cholesterol and $20 \%$ mole DOPE resulted in a broadening of the transition peak and a significant decrease in the enthalpy of the main transition to $12.8 \mathrm{~kJ} / \mathrm{mol}$ compared with the formulations containing only drugs and DPPC $(p<0.05)$. A decrease in enthalpy is attributed to weakening of van der Waals interactions within the phospholipid bilayer, with increased disorder of the hydrocarbon chains (Gardikis et al., 2006). There was a significant increase in the width of the main endotherm at half height (HHW) for individual, co-loaded DPPC liposomes and the final formulation compared with DPPC liposomes (Table 2, p<0.05). HHW indicates the size of cooperative unit involved in the transition, with increased HHW indicating a reduction of cooperative unit within bilayer (Cong et al., 2009; $\underline{\text { Saunders }}$ et al., 2007) These results are in a good agreement with previous reports of pre and main transition temperatures and enthalpies of transition for DPPC-based liposomes (Beni et al., 2006; Hadian et al., 2014). 
Overall, the DSC results indicate incorporation of both drug molecules into DPPC liposomes, increasing bilayer fluidity and disrupting the packing of the acyl chain domain. Broadening of the main phase transition endotherm and reduction in the main transition temperature of DPPC suggest that that drug molecules were located inside the hydrophobic bilayer, including within the upper regions of the hydrophobic chains $\left(\mathrm{C}_{1}-\mathrm{C}_{8}\right)$ close to the polar head group of DPPC (Taylor and Morris, 1995). These data confirm that erlotinib and genistein were successfully incorporated into DPPC liposomes and are in agreement with the results of drug loading-efficiency.

3.4 Comparison of aerosol properties using the Next Generation Impactor (NGI) and the Fast Screening Impactor (FSI) for liposomal preparations delivered from an air-jet nebuliser

The amount of active pharmaceutical ingredients emitted from the nebuliser and the FPM/FPD are key parameters which will impact clinical outcomes.

The nebuliser fill volume, duration time of nebulisation and solvent for rinsing the nebuliser and impactor were optimised in preliminary studies. Initial experiments investigated $2 \mathrm{~mL}$ and $4 \mathrm{~mL}$ fill volumes of optimised liposomes and 5 and $10 \mathrm{~min}$ nebulisation times. However, erlotinib deposited across all eight stages of the NGI could not be accurately quantified using the validated HPLC method, as in some individual stages the concentration of erlotinib in collected samples was lower than the limit of quantification. The two-stage abbreviated impactor (FSI) was evaluated at the air-flow rate of $15 \mathrm{~L} / \mathrm{min}$ as an alternative to overcome this problem and provide a more rapid analysis. The mass balance with both the NGI and FSI for both drugs was within European Pharmacopeia acceptance limits. Using the FSI for erlotinib and genistein, the emitted dose was approximately $30 \%$ for both drugs (Table 3 ). These values were not significantly different ( $>>0.05$ ) from those obtained with the NGI (Table 3). The NGI gave higher values of Fine Particle Fraction $(\%$ FPF $)$ compared to FSI $(p<0.05)$ for both drugs. The Fine Particle Dose (FPD) for genistein using NGI was also significantly higher than with FSI $(\mathrm{p}<0.05)$, while there were no significant differences in FPD for erlotinib ( $p>0.05)$.

Differences in measured values between impactors are to be expected and may result 
from the longer flight path and transit times of droplets through the internal volume of the NGI compared to the FSI, allowing increased thermal-transfer related water loss and causing the droplets to shrink (Dennis et al., 2008; Kuhli et al., 2009). Moreover, the large headspace of the FSI in comparison with the NGI could also possibly enhance the water evaporation effect. Furthermore, the differences in the way FPF and FPD are determined when using the two impactors may lead to significant differences in calculated values. For the FSI, the fraction less than $5 \mu \mathrm{m}$ is based on the mass of drug collected from stage 2, whilst for the NGI, it is calculated by interpolation from data based on mass of drug collected in all stages of the impactor.

There was a slight change in FPD of erlotinib between the NGI and FSI contributing to a significant change in FPF as seen in Table 3. This can be attributed to the factors outlined above. It is noted that the erlotinib deposited on all collecting cups of the NGI could not be accurately quantified due to low levels of deposition, below the limit of quantification (LOQ), whereas genistein could be accurately quantified (all values above the LOQ) using both impactors. Both impactors can be compared based on full quantification of genistein.

The two impactors gave different but comparable values for the key parameters of FPF and FPD with the same value for emitted dose or output rate under the same operating conditions. The FSI allowed more rapid determination of these key parameters and overcame the problem of accurate quantification of erlotinib at the low levels of deposition on some stages of the NGI.

\subsection{Aerosol characterisation using the FSI}

The emitted doses measured in the initial experiments were low, being approximately $30 \%$ for both drugs. Further studies focused on a number of factors that might affect emitted dose: air-flow rate through the impactor, FSI temperature and type of nebuliser.

\subsubsection{Effect of air-flow rate on aerosol properties}

Whilst there were no significant differences in emitted dose $(p>0.05)$ for air-jet nebulisers at the two impactor flow rates, there was an almost halving of FPF, from 
approximately $70 \%$ to $40 \%$ for both drugs when an air-flow rate of $15 \mathrm{~L} / \mathrm{min}$ rather than $30 \mathrm{~L} / \mathrm{min}$ was employed (Fig. 1). The FPD was also lower for both drugs using air-jet nebulisers at the lower flow rate through the FSI, this difference was significant for the aerosol of genistein $(\mathrm{p}<0.05)$, but not erlotinib which exhibited greater variability at the higher flow rate $(p>0.05$; Table 4$)$. The reason for the difference between drugs is unclear, but may result from differences in solubility and liposomal inclusion of the two hydrophobic drugs as the temperature within the air-jet nebuliser reservoir decreases over the nebulisation period, concentration changes due to enhanced solvent loss during atomisation, and/or disruption of liposome bilayers during nebulisation (Chan et al., 2011; Elhissi et al., 2012; Rudokas et al., 2016). The variability in FPD of both drugs at the flow rate of $30 \mathrm{~L} / \mathrm{min}$ was obviously higher than at the flow rate of $15 \mathrm{~L} / \mathrm{min}$ as seen in Table 4 , possibly be due to the enhanced water evaporation, decreasing droplet size at higher air flow (Berg et al., 2007).

\subsubsection{Effect of pre-cooling FSI on measured aerosol properties}

Table 5 shows that the measured FPF was not significantly different ( $p>0.05)$ at 15 $\mathrm{L} / \mathrm{min}$ for the two different temperatures, while the value of FPD performed at ambient temperature was comparatively high for both drugs. At the air-flow rate of $30 \mathrm{~L} / \mathrm{min}$, the FPF for genistein decreased considerably $(\mathrm{p}<0.05)$ when ambient temperature (approximately $20^{\circ} \mathrm{C}$ ) was employed, while the value of FPD was not significantly different (Table 5). The FPD (which is a function of FPF and emitted dose) of erlotinib using the non-cooled FSI at 30L/min was relatively high, while there were no significant differences in FPF compared with cooled FSI ( $p>0.05)$. The results showed that the impactor temperature had less impact on the FPF, than on emitted dose. The precise mechanism of heat transfer to aerosol droplets throughout the FSI is uncertain; however, the shorter flight path is likely to lead to a lower thermal capacity compared to the NGI; both impactors being constructed from metal. On the other hand, the high dead volume of the FSI may allow enhanced water loss when ambient air is used to draw nebulized liposomes through the chilled FSI. This could result in the similar results of aerosolisation using non-cooled and cooled FSI. These factors should be taken into consideration in further studies. Omission of cooling, as required by $\mathrm{Ph}$. Eur. for the NGI, would be advantageous in routine quality control, though further 
investigation is required with other formulations having different physicochemical properties. A cooled FSI was used in further investigation using the mesh nebuliser, to allow comparison with the NGI operated under the same operating conditions.

\subsubsection{Measured aerosol properties for air-jet and vibrating-mesh nebulisers}

Vibrating-mesh nebulisers were studied as they are reported to have high aerosol and drug output rates, and have been reported as highly suited for delivering liposomal aerosols (Elhissi et al., 2011; Lass et al., 2006; Pitance et al., 2010). The aerosol characteristics for the liposome formulation delivered using vibrating-mesh and air-jet nebulisers were similar. The FPF increased $(\mathrm{p}<0.05)$ with increasing flow rate through the FSI, from approximately $20 \%$ to $40 \%$ for both drugs, with no significant changes in emitted dose ( $p>0.05$ ) (Fig. 2). Significantly higher FPDs for erlotinib and genistein were also observed $(\mathrm{p}<0.05)$ at the air-flow rate of $30 \mathrm{~L} / \mathrm{min}$ as seen in Table 4.

As expected, erlotinib and genistein deposition was comparable in all cases, being coloaded into liposomes significantly smaller than the aerosol droplets produced by either nebuliser type. Differences in FPD, a critical quality parameter impactor reflected those for FPF, as expected given the similarities in emitted dose at both flow rates (EMA guideline, 2006) (Table 4). Changes in air-flow rates through the impactor with both nebuliser types have an artefactual effect on measured parameters depending on aerosol size (FPF and FPD) with higher flow rates, resulting in reduced droplet sizes due to evaporative losses.

Air-jet nebulisers were found to be more efficient than vibrating-mesh devices in this study, generating liposomal aerosols having approximately two-fold greater FPF at both impactor flow rates (Fig. 1 and 2). FPD values were more comparable between nebuliser types (Table 4), because of the higher emitted dose achieved with the mesh devices, as previously reported (Lass et al., 2006; Pitance et al., 2010).

From the findings described, the air-jet nebuliser would appear preferable to that based on vibrating-mesh technology for this specific liposome formulation. The lower efficiency of the vibrating-mesh nebuliser in comparison with air-jet nebuliser for delivering this formulation may be due to the lower energy input for atomisation, lack 
of an ionic component (particularly a halide) or a surfactant in the formulation and the generation of heat possibly resulting in the liposome aggregation/degradation during $10 \mathrm{~min}$ nebulisation as previously reported for thermolabile proteins (Beck-Broichsitter and Oesterheld, 2017; Hertel et al., 2014). Furthermore, the mesh pore could possibly be blocked due to drug crystallisation or inappropriate properties of formulation during nebulisation, resulting in higher resistance when the diameter of mesh apertures was decreased (Chan et al., 2011; Manunta et al., 2011). Another possible reason is the differences in temperature of emitted aerosol droplets using two nebuliser systems. The temperature of aerosol emitted from air-jet is approximately $10{ }^{\circ} \mathrm{C}$ cooler than ambient inlet air, whereas the temperature of those from vibrating-mesh nebuliser is similar to ambient temperature (Abdelrahim and Chrystyn, 2009). Consequently, the water evaporation effect using the FSI operated at both air-flow rates for air-jet was likely greater with the vibrating-mesh nebuliser, resulting in higher FPF.

To further investigate the implications of these findings, the measured aerosol properties and nebuliser performance should be studied in relation to the physicochemical properties of formulations during atomization; for example, viscosity and surface tension, along with the impact of including surfactants and electrolytes/halides in formulations.

\subsubsection{Size and morphology of liposomes before and after nebulisation}

Table 6 shows the results of particle size analysis for freshly sonicated liposomes before and after nebulisation into the FSI.

The measured mean size of sonicated liposomes indicated that the liposomes remaining in the nebuliser reservoir for air-jet nebulisers and on the additional insert (Stage 1 of the FSI housing) was approximately three-fold higher than measured before nebulisation and the PDI value increased considerably $(\mathrm{p}<0.05)$. This suggests that some vesicles fused, fractured and reformed and/or aggregated in the main reservoir resulting in widening of size distribution (Elhissi et al., 2012). The size of sonicated liposomes in the lower stage was also larger than the starting size but smaller than other regions. 
The mean size and PDI of nebulised sonicated liposomes using the vibrating-mesh nebuliser increased considerably compared with starting size in the main reservoir and upper stage of the FSI $(\mathrm{p}<0.05)$. This suggests that some large liposomes aggregate or accumulate in the nebuliser reservoir and fail to pass through the mesh apertures, whereas the slight decrease in size of liposomes deposited on lower stage (Elhissi et al., $\underline{2011})$.

The mean size of liposomes delivered by both nebuliser devices to the lower stage was smaller than those remaining in the nebuliser reservoir and on the upper stage of the impactor. This may predominantly result from the water evaporation effect during delivered throughout the impactor and/or liposome disruption after being delivered from nebulisers. A reduction in the size of vesicles deposited in the lower as opposed to higher stages of a full-impactor has been previously reported following nebulisation from an air-jet nebuliser (Manca et al 2015). Overall, it can be seen that there was no difference in size stability of nebulised liposomes delivered by air-jet and vibratingmesh nebuliser.

TEMs showed no apparent changes in vesicle shape or morphology during nebulisation from either type of nebuliser. TEMs of sonicated MLVs (Figure 3A) prior to nebulisation, show a population of small spherical liposomes, with a single of few lamellae. TEMs of vesicles remaining in the air-jet nebuliser following sonication (Figure 3B) and those collected in the upper stage (Figure 3C) and lower stage of the FSI (Figure 3D) show no evident morphological changes.

\section{Conclusions}

An optimised co-loaded liposome formulation for pulmonary delivery was successfully prepared by the conventional thin-film hydration method, followed by probe sonication. The Fast Screening impactor (FSI), comprising only two impaction stages, has been shown to be simple, labour and time-saving for aerosol characterisation, giving comparable results to the NGI for key parameters such as FPD and FPF. The FSI is thus a useful alternative technique for characterising the aerosol properties of nebulised formulations, particularly when pre-cooled and used at $15 \mathrm{~L} / \mathrm{min}$, with appropriate modification to the insert. An air-jet nebuliser was found superior to a 
vibrating-mesh technology, for delivery of the co-loaded liposomes over a 10-min period, in terms of higher FPF and emitted dose. Improvement in the delivery of liposomal formulations using vibrating-mesh nebulisers requires further study.

\section{Acknowledgements}

The authors would like to thank Dr. Hardyal S. Gill (UCL) for his assistance with the HPLC analysis, Mr David McCarthy (UCL) for his help with the TEM images and Dr. Asma Buanz (UCL) for her expertise with DSC.

\section{References}

Abdelrahim, M.E., 2011. Aerodynamic characteristics of nebulized terbutaline sulphate using the Andersen Cascade Impactor compared to the Next Generation Impactor. Pharmaceutical Development and Technology 16, 137-145.

Amini, M.A., Faramarzi, M.A., Gilani, K., Moazeni, E., Esmaeilzadeh-Gharehdaghi, E., Amani, A., 2014. Production, characterisation, and in vitro nebulisation performance of budesonide-loaded PLA nanoparticles. Journal of Microencapsulation $31,422-429$.

Beck-Broichsitter, M., Oesterheld, N., 2017. Electrolyte type and nozzle composition affect the process of vibrating-membrane nebulization. European Journal of Pharmaceutics and Biopharmaceutics 119, 11-16.

Beni, S., Budai, M., Noszal, B., Grof, P., 2006. Molecular interactions in imatinibDPPC liposomes. European Journal of Pharmaceutical Sciences : official journal of the European Federation for Pharmaceutical Sciences 27, 205-211.

Berg, E., Svensson, J.O., Asking, L., 2007. Determination of nebulizer droplet size distribution: a method based on impactor refrigeration. Journal of Aerosol Medicine : the official journal of the International Society for Aerosols in Medicine 20, 97-104.

Bridges, P.A., Taylor, K.M.G., 2000. An investigation of some of the factors influencing the jet nebulisation of liposomes. International Journal of Pharmaceutics 204, 69-79. 
Budai, M., Szabó, Z., Szőgyi, M., Gróf, P., 2003. Molecular interactions between DPPC and morphine derivatives: a DSC and EPR study. International Journal of Pharmaceutics 250, 239-250.

Chan, J.G., Kwok, P.C., Young, P.M., Chan, H.K., Traini, D., 2011. Mannitol delivery by vibrating mesh nebulisation for enhancing mucociliary clearance. Journal of Pharmaceutical Sciences 100, 2693-2702.

Chen, J., He, C.Q., Lin, A.H., Xu, F., Wang, F., Zhao, B., Liu, X., Chen, Z.P., Cai, B.C., 2014. Brucine-loaded liposomes composed of HSPC and DPPC at different ratios: in vitro and in vivo evaluation. Drug Development and Industrial Pharmacy 40, 244-251.

Cipolla, D., Gonda, I., Chan, H.K., 2013. Liposomal formulations for inhalation. Therapeutic Delivery 4, 1047-1072.

Cong, W., Liu, Q., Liang, Q., Wang, Y., Luo, G., 2009. Investigation on the interactions between pirarubicin and phospholipids. Biophysical Chemistry 143, 154160.

Dandekar, P., Venkataraman, C., Mehra, A., 2010. Pulmonary targeting of nanoparticle drug matrices. Journal of Aerosol Medicine and Pulmonary Drug Delivery 23, 343-353.

Demetzos, C., 2008. Differential Scanning Calorimetry (DSC): a tool to study the thermal behavior of lipid bilayers and liposomal stability. Journal of Liposome Research 18, 159-173.

Dennis, J., Berg, E., Sandell, D., Ali, A., Lamb, P., Tservistas, M., Karlsson, M., Mitchell, J., 2008. Cooling the NGI - an approach to size a nebulised aerosol more accurately. Pharmeuropa Scientific Notes 2008, 27-30.

Eckert, G.P., Chang, S., Eckmann, J., Copanaki, E., Hagl, S., Hener, U., Muller, W.E., Kogel, D., 2011. Liposome-incorporated DHA increases neuronal survival by enhancing non-amyloidogenic APP processing. Biochimica et Biophysica Acta 1808, 236-243.

El-Gendy, N., Selvam, P., Soni, P., Berkland, C., 2012. Development of budesonide nanocluster dry powder aerosols: processing. Journal of Pharmaceutical Sciences 101, 3425-3433.

Elhissi, A., Hidayat, K., Phoenix, D.A., Mwesigwa, E., Crean, S., Ahmed, W., Faheem, A., Taylor, K.M.G., 2013. Air-jet and vibrating-mesh nebulization of niosomes generated using a particulate-based proniosome technology. International Journal of Pharmaceutics 444, 193-199.

Elhissi, A.M.A., Giebultowicz, J., Stec, A.A., Wroczynski, P., Ahmed, W., Alhnan, M.A., Phoenix, D., Taylor, K.M.G., 2012. Nebulization of ultradeformable liposomes: the influence of aerosolization mechanism and formulation excipients. International Journal of Pharmaceutics 436, 519-526. 
Elhissi, A.M.A., Gill, H., Ahmed, W., Taylor, K.M.G., 2011. Vibrating-mesh nebulization of liposomes generated using an ethanol-based proliposome technology. Journal of Liposome Research 21, 173-180.

Elhissi, A.M.A., Karnam, K.K., Danesh-Azari, M.R., Gill, H.S., Taylor, K.M.G., 2006a. Formulations generated from ethanol-based proliposomes for delivery via medical nebulizers. The Journal of Pharmacy and Pharmacology 58, 887-894.

Elhissi, A.M.A., O’Neill, M.A.A., Roberts, S.A., Taylor, K.M.G., 2006b. A calorimetric study of dimyristoylphosphatidylcholine phase transitions and steroidliposome interactions for liposomes prepared by thin film and proliposome methods. International Journal of Pharmaceutics 320, 124-130.

European Pharmacoepia 9.0, 2017. Section 2.9.44.-Preparations for nebulisation characterisation, Strasbourg: Council of Europe, 378-381.

European Medicines Agency, 2006. Guideline on the pharmaceutical quality of inhalation and nasal products, London, UK, 1-27.

Gadgeel, S.M., Ali, S., Philip, P.A., Wozniak, A., Sarkar, F.H., 2009. Genistein enhances the effect of epidermal growth factor receptor tyrosine kinase inhibitors and inhibits nuclear factor kappa B in nonsmall cell lung cancer cell lines. Cancer 115, 2165-2176.

Gardikis, K., Hatziantoniou, S., Viras, K., Wagner, M., Demetzos, C., 2006. A DSC and Raman spectroscopy study on the effect of PAMAM dendrimer on DPPC model lipid membranes. International Journal of Pharmaceutics 318, 118-123.

Guo, C., Ngo, D., Ahadi, S., Doub, W.H., 2013. Evaluation of an Abbreviated Impactor for Fine Particle Fraction (FPF) Determination of Metered Dose Inhalers (MDI). AAPS PharmSciTech 14, 1004-1011.

Hadian, Z., Sahari, M.A., Moghimi, H.R., Barzegar, M., 2014. Formulation, characterization and optimization of liposomes containing eicosapentaenoic and docosahexaenoic acids; a methodology approach. Iranian Journal of Pharmaceutical Research 13, 393-404.

Hassanzadeh, F., Farzan, M., Varshosaz, J., Khodarahmi, G.A., Maaleki, S., Rostami, M., 2017. Poly (ethylene-co-vinyl alcohol)-based polymeric thermo-responsive nanocarriers for controlled delivery of epirubicin to hepatocellular carcinoma. Research in Pharmaceutical Sciences 12, 107-118.

Hertel, S., Pohl, T., Friess, W., Winter, G., 2014. That's cool! - Nebulization of thermolabile proteins with a cooled vibrating mesh nebulizer. European Journal of Pharmaceutics and Biopharmaceutics 87, 357-365.

Holmkvist, A.D., Friberg, A., Nilsson, U.J., Schouenborg, J., 2016. Hydrophobic ion pairing of a minocycline/Ca2+/AOT complex for preparation of drug-loaded PLGA 
nanoparticles with improved sustained release. International Journal of Pharmaceutics 499, 351-357.

Hong, S.S., Choi, J.Y., Kim, J.O., Lee, M.K., Kim, S.H., Lim, S.J., 2016.

Development of paclitaxel-loaded liposomal nanocarrier stabilized by triglyceride incorporation. International Journal of Nanomedicine 11, 4465-4477.

ICH, 2005. Validation of analytical procedures; text and methodology Q2 (R1). <http://www.ich.org> (accessed 22.1.1.15).

ISO-22412, 2008. Particle Size Analysis, Dynamic Light Scattering (DLS), International Organization for Standardization.

Johal, B., Howald, M., Fischer, M., Marshall, J., Venthoye, G., 2013. Fine particle profile of fluticasone propionate/formoterol fumarate versus other combination products: the DIFFUSE Study. Combination Products in Therapy 3, 39-51.

Kannan, V., Balabathula, P., Divi, M.K., Thoma, L.A., Wood, G.C., 2015. Optimization of drug loading to improve physical stability of paclitaxel-loaded longcirculating liposomes. Journal of Liposome Research 25, 308-315.

Kendrick, A.H., Smith, E.C., Wilson, R.S., 1997. Selecting and using nebuliser equipment. Thorax 52, S92-S101.

Kuhli, M., Weiss, M., Steckel, H., 2009. A sampling and dilution system for droplet aerosols from medical nebulisers developed for use with an optical particle counter. Journal of Aerosol Science 40, 523-533.

Lass, J.S., Sant, A., Knoch, M., 2006. New advances in aerosolised drug delivery: vibrating membrane nebuliser technology. Expert Opinion on Drug Delivery 3, 693702.

Li, Q., Cai, T., Huang, Y., Xia, X., Cole, S.P.C., Cai, Y., 2017. A review of the structure, preparation, and application of NLCs, PNPs, and PLNs. Nanomaterials (Basel, Switzerland) 7, 1-25.

Mahajan, H.S., Mahajan, P.R., 2016. Development of grafted xyloglucan micelles for pulmonary delivery of curcumin: In vitro and in vivo studies. International Journal of Biological Macromolecules 82, 621-627.

Manca, M.L., Peris, J.E., Melis, V., Valenti, D., Cardia, M.C., Lattuada, D., Escribano-Ferrer, E., Fadda, A.M., Manconi, M., 2015. Nanoincorporation of curcumin in polymer-glycerosomes and evaluation of their in vitro-in vivo suitability as pulmonary delivery systems. RSC Advances 5, 105149-105159.

Manca, M.L., Sinico, C., Maccioni, A.M., Diez, O., Fadda, A.M., Manconi, M., 2012. Composition influence on pulmonary delivery of rifampicin liposomes.

Pharmaceutics 4, 590-606. 
Manca, M.L., Valenti, D., Sales, O.D., Nacher, A., Fadda, A.M., Manconi, M., 2014. Fabrication of polyelectrolyte multilayered vesicles as inhalable dry powder for lung administration of rifampicin. International Journal of Pharmaceutics 472, 102-109.

Manca, M.L., Zaru, M., Manconi, M., Lai, F., Valenti, D., Sinico, C., Fadda, A.M., 2013. Glycerosomes: A new tool for effective dermal and transdermal drug delivery. International Journal of Pharmaceutics 455, 66-74.

Mandal, B., Mittal, N.K., Balabathula, P., Thoma, L.A., Wood, G.C., 2016. Development and in vitro evaluation of core-shell type lipid-polymer hybrid nanoparticles for the delivery of erlotinib in non-small cell lung cancer. European Journal of Pharmaceutical Sciences : official journal of the European Federation for Pharmaceutical Sciences 81, 162-171.

Manunta, M.D., McAnulty, R.J., Tagalakis, A.D., Bottoms, S.E., Campbell, F., Hailes, H.C., Tabor, A.B., Laurent, G.J., O'Callaghan, C., Hart, S.L., 2011.

Nebulisation of receptor-targeted nanocomplexes for gene delivery to the airway epithelium. PloS one 6, 1-13.

Mitchell, J.P., Nagel, M.W., Avvakoumova, V., MacKay, H., Ali, R., 2009. The Abbreviated Impactor Measurement (AIM) Concept: Part 1-Influence of particle bounce and re-entrainment - Evaluation with a "Dry" Pressurized Metered Dose Inhaler (pMDI)-based formulation. AAPS PharmSciTech 10, 243-251.

Mohan, M., Lee, S., Guo, C., Peri, S.P., Doub, W.H., 2017. Evaluation of Abbreviated Impactor Measurements (AIM) and Efficient Data Analysis (EDA) for Dry Powder Inhalers (DPIs) against the full-resolution Next Generation Impactor (NGI). AAPS PharmSciTech 18, 1585-1594.

Phan, V., Walters, J., Brownlow, B., Elbayoumi, T., 2013. Enhanced cytotoxicity of optimized liposomal genistein via specific induction of apoptosis in breast, ovarian and prostate carcinomas. Journal of Drug Targeting 21, 1001-1011.

Pitance, L., Vecellio, L., Leal, T., Reychler, G., Reychler, H., Liistro, G., 2010. Delivery efficacy of a vibrating mesh nebulizer and a jet nebulizer under different configurations. Journal of Aerosol Medicine and Pulmonary Drug Delivery 23, 389396.

Rasti, B., Jinap, S., Mozafari, M.R., Yazid, A.M., 2012. Comparative study of the oxidative and physical stability of liposomal and nanoliposomal polyunsaturated fatty acids prepared with conventional and Mozafari methods. Food Chemistry 135, 27612770.

Rudokas, M., Najlah, M., Alhnan, M.A., Elhissi, A., 2016. Liposome delivery systems for inhalation: a critical review highlighting formulation issues and anticancer applications. Medical principles and practice : International Journal of the Kuwait University, Health Science Centre 25 Suppl 2, 60-72. 
Saunders, M., Taylor, K.M., Craig, D.Q., Palin, K., Robson, H., 2007. High sensitivity differential scanning calorimetry study of DNA-cationic liposome complexes. Pharm Res 24, 1954-1961.

Sercombe, L., Veerati, T., Moheimani, F., Wu, S.Y., Sood, A.K., Hua, S., 2015. Advances and challenges of liposome assisted drug delivery. Frontiers in Pharmacology 6, 286.

Taylor, K.M.G., Morris, R.M., 1995. Thermal analysis of phase transition behaviour in liposomes. Thermochimica Acta 248, 289-301.

Tservistas, M., Uhlig, M., Mitchell, J., 2010. Assessment of Abbreviated Impactor Measurement (AIM) methods for nebulizer characterization. DDL Conference, 1-5.

Vyas, S.P., Kannan, M.E., Jain, S., Mishra, V., Singh, P., 2004. Design of liposomal aerosols for improved delivery of rifampicin to alveolar macrophages. International Journal of Pharmaceutics 269, 37-49.

Xie, Y.T., Du, Y.Z., Yuan, H., Hu, F.Q., 2012. Brain-targeting study of stearic acidgrafted chitosan micelle drug-delivery system. International Journal of Nanomedicine 7, 3235-3244.

Zhao, L., Feng, S.S., Kocherginsky, N., Kostetski, I., 2007. DSC and EPR investigations on effects of cholesterol component on molecular interactions between paclitaxel and phospholipid within lipid bilayer membrane. International Journal of Pharmaceutics 338, 258-266.

Zhou, Y., Ahuja, A., Irvin, C.M., Kracko, D.A., McDonald, J.D., Cheng, Y.S., 2005. Medical nebulizer performance: effects of cascade impactor temperature. Respiratory Care 50, 1077-1082.

Table 1. Hydrodynamic diameter, Polydispersity Index (PDI), zeta potential and drug encapsulation (\% EE) for co-loaded liposomes before and after separating non-incorporated drugs by filtration $(n=3$, mean \pm S.D. $)$

\begin{tabular}{|c|l|l|l|l|}
\hline Size reduction method & $\begin{array}{l}\text { Hydrodynamic } \\
\text { diameter (nm) }\end{array}$ & PDI & $\begin{array}{l}\text { Zeta } \\
\text { potential } \\
(\mathbf{m V})\end{array}$ & $\% \mathbf{E E}$ \\
\hline $\begin{array}{c}\text { Probe-sonication } \\
\text { Pre-filtration }\end{array}$ & $214.63 \pm 25.69$ & $0.71 \pm 0.08$ & $+0.66 \pm 0.54$ & - \\
Post-filtration & $139.3 \pm 2.42$ & $0.56 \pm 0.03$ & $+0.27 \pm 0.05$ & $\begin{array}{l}8.57 \pm 1.06 \quad(\text { Erlo) } \\
100.13 \pm 1.15 \text { (Gen) }\end{array}$ \\
\hline
\end{tabular}


Table 2. DSC parameters for individual and co-loaded liposomes $(n=3$, mean \pm S.D.)

\begin{tabular}{|c|c|c|c|c|}
\hline $\begin{array}{c}\text { Type of } \\
\text { formulations }\end{array}$ & Pre-transition & \multicolumn{3}{|c|}{ Main transition } \\
\hline & ${ }^{1} \mathrm{~T}_{\mathrm{pre}}\left({ }^{\circ} \mathrm{C}\right)$ & ${ }^{2} \mathrm{~T}_{\mathrm{m}}\left({ }^{\circ} \mathrm{C}\right)$ & ${ }^{3} \mathrm{HHW}\left({ }^{\circ} \mathrm{C}\right)$ & Enthalpy $(\mathrm{kJ} / \mathrm{mol})$ \\
\hline DPPC liposomes & $39.36 \pm 0.29$ & $42.74 \pm 0.28$ & $1.68 \pm 0.16$ & $37.35 \pm 3.06$ \\
\hline
\end{tabular}

${ }^{1} \mathrm{~T}_{\text {pre }}=$ The temperature of the pre-transition

${ }^{2} \mathrm{~T}_{\mathrm{m}}=$ The main phase transition temperature

${ }^{3} \mathrm{HHW}=$ Half Height Width of the main endothermic peak 


\begin{tabular}{|l|c|c|c|c|}
\hline $\begin{array}{l}2.5 \% \text { w/w co-loaded } \\
\text { liposomes }\end{array}$ & - & $41.34 \pm 0.28$ & $2.40 \pm 0.07$ & $40.02 \pm 0.69$ \\
\hline $\begin{array}{l}2.5 \% \text { w/w erlotinib } \\
\text { loaded DPPC } \\
\text { liposomes }\end{array}$ & $39.21 \pm 0.28$ & $42.73 \pm 0.27$ & $2.26 \pm 0.11$ & $39.30 \pm 1.50$ \\
\hline $\begin{array}{l}2.5 \% \text { w/w genistein } \\
\text { loaded DPPC } \\
\text { liposomes }\end{array}$ & - & $41.63 \pm 0.22$ & $2.29 \pm 0.11$ & $40.53 \pm 1.01$ \\
\hline $\begin{array}{l}2.5 \% \text { w/w co-loaded } \\
\text { DPPC }+8 \% \text { mole of } \\
\text { cholesterol liposomes }\end{array}$ & - & $41.55 \pm 0.01$ & $2.50 \pm 0.15$ & $31.89 \pm 2.89$ \\
\hline $\begin{array}{l}2.5 \% \text { w/w co-loaded } \\
72 \% \text { mole of DPPC }+ \\
8 \% \text { mole of } \\
\text { cholesterol and } 20 \% \\
\text { mole of DOPE } \\
\text { liposomes }\end{array}$ & - & $36.71 \pm 0.29$ & $9.30 \pm 0.20$ & $12.86 \pm 0.79$ \\
\hline
\end{tabular}

Table 3. Aerosol parameters of co-loaded liposomal aerosols delivered from an air-jet nebuliser into the cooled NGI and FSI at air-flow rate of $15 \mathrm{~L} / \mathrm{min}$ for 10 $\min (n=3$, mean \pm S.D. $)$ 


\begin{tabular}{|lc|c|c|}
\hline \multicolumn{2}{|c|}{ Aerosol parameters } & NGI & FSI \\
\hline Mass balance $(\%)$ & $($ Erlo $)$ & $83.09 \pm 4.04$ & $81.21 \pm 5.08$ \\
& $($ Gen $)$ & $85.44 \pm 1.49$ & $82.91 \pm 2.28$ \\
\hline${ }^{4} \mathrm{ED}(\%)$ & $($ Erlo $)$ & $32.05 \pm 3.57$ & $30.52 \pm 2.84$ \\
& $($ Gen $)$ & $34.42 \pm 0.92$ & $34.31 \pm 5.86$ \\
\hline${ }^{5} \mathrm{FPD}(\mu \mathrm{g})$ & $($ Erlo $)$ & $22.33 \pm 3.75$ & $18.02 \pm 2.51$ \\
& $($ Gen $)$ & $328.33 \pm 36.17$ & $224.24 \pm 10.14$ \\
\hline${ }^{6} \mathrm{FPF}(\%)$ & $($ Erlo $)$ & $62.00 \pm 5.29$ & $45.55 \pm 6.16$ \\
& $($ Gen $)$ & $58.33 \pm 4.51$ & $42.55 \pm 6.28$ \\
\hline
\end{tabular}

Table 4. Fine particle dose for co-loaded liposomal aerosols delivered by air-jet and vibrating-mesh nebulisers operated at $15 \mathrm{~L} / \mathrm{min}$ and $30 \mathrm{~L} / \mathrm{min}$ using the cooled FSI $(n=3$, mean \pm S.D. $)$

\footnotetext{
${ }^{4} \mathrm{ED} \quad=$ Emitted Dose

${ }^{5} \mathrm{FPD}=$ Fine Particle Dose or Fine Particle Mass

${ }^{6} \mathrm{FPF}=$ Fine Particle Fraction
} 


\begin{tabular}{|c|c|c|c|}
\hline Type of nebuliser & Air-flow rate (L/min) & Fine Particle D & se $(\mu g)$ \\
\hline \multirow{2}{*}{ Air-jet } & 15 & $\begin{array}{l}18.02 \pm 2.51 \\
224.24 \pm 10.14\end{array}$ & $\begin{array}{l}\text { (Erlo) } \\
\text { (Gen) }\end{array}$ \\
\hline & 30 & $\begin{array}{l}25.93 \pm 9.17 \\
326.87 \pm 37.91\end{array}$ & $\begin{array}{l}\text { (Erlo) } \\
\text { (Gen) }\end{array}$ \\
\hline \multirow{2}{*}{ Vibrating-mesh } & 15 & $\begin{array}{l}17.25 \pm 1.72 \\
149.14 \pm 41.52\end{array}$ & $\begin{array}{l}\text { (Erlo) } \\
\text { (Gen) }\end{array}$ \\
\hline & 30 & $\begin{array}{l}32.83 \pm 4.44 \\
269.83 \pm 13.33\end{array}$ & $\begin{array}{l}\text { (Erlo) } \\
(\text { Gen })\end{array}$ \\
\hline
\end{tabular}

Table 5. Fine particle dose for co-loaded liposomal aerosols delivered by air-jet nebulisers measured using FSI at different temperatures and air-flow rates $(n=3$, mean \pm S.D.) 


\begin{tabular}{|c|c|c|c|c|}
\hline Temperature & $\begin{array}{l}\text { Air-flow rate } \\
\text { (L/min) }\end{array}$ & $\begin{array}{l}\text { Emitted Dose } \\
(\%)\end{array}$ & $\begin{array}{l}\text { Fine Particle } \\
\text { Fraction }(\%)\end{array}$ & $\begin{array}{l}\text { Fine Particle } \\
\text { Dose }(\mu \mathrm{g})\end{array}$ \\
\hline $5^{\circ} \mathrm{C}$ & 15 & $\begin{array}{l}30.52 \pm 2.84 \\
(\text { Erlo) } \\
34.31 \pm 5.86 \\
(\text { Gen })\end{array}$ & $\begin{array}{l}45.55 \pm 6.16 \\
(\text { Erlo) } \\
42.55 \pm 6.28 \\
(\text { Gen })\end{array}$ & $\begin{array}{l}18.02 \pm 2.51 \\
(\text { Erlo) } \\
224.24 \pm 10.14 \\
\text { (Gen) }\end{array}$ \\
\hline $\begin{array}{l}\text { Ambient } \\
\text { temperature }\end{array}$ & 15 & $\begin{array}{l}53.23 \pm 4.37 \\
\text { (Erlo) } \\
47.57 \pm 1.96 \\
(\text { Gen) }\end{array}$ & $\begin{array}{l}48.03 \pm 9.57 \\
(\text { Erlo }) \\
42.97 \pm 10.50 \\
(\text { Gen })\end{array}$ & $\begin{array}{l}38.19 \pm 2.76 \\
(\text { Erlo) } \\
327.66 \pm 91.77 \\
(\text { Gen) }\end{array}$ \\
\hline $5^{\circ} \mathrm{C}$ & 30 & $\begin{array}{l}26.92 \pm 4.17 \\
(\text { Erlo) } \\
27.93 \pm 1.81 \\
(\text { Gen })\end{array}$ & $\begin{array}{l}73.37 \pm 11.83 \\
(\text { Erlo) } \\
73.17 \pm 6.10 \\
(\text { Gen })\end{array}$ & $\begin{array}{l}25.93 \pm 9.17 \\
(\text { Erlo) } \\
326.87 \pm 37.91 \\
(\text { Gen })\end{array}$ \\
\hline $\begin{array}{l}\text { Ambient } \\
\text { temperature }\end{array}$ & 30 & $\begin{array}{l}60.88 \pm 7.82 \\
(\text { Erlo) } \\
56.99 \pm 7.16 \\
(\text { Gen })\end{array}$ & $\begin{array}{l}55.17 \pm 7.15 \\
\text { (Erlo) } \\
50.17 \pm 6.44 \\
\text { (Gen) }\end{array}$ & $\begin{array}{l}48.44 \pm 10.44 \\
(\text { Erlo) } \\
420.74 \pm 101.61 \\
\text { (Gen) }\end{array}$ \\
\hline
\end{tabular}

Table 6. Hydrodynamic diameter (Z-ave) and Polydispersity Index (PDI) of nebulised co-loaded liposomes delivered to the FSI stages, and those remaining in the nebuliser reservoir $(n=3$, mean \pm S.D. $)$ 


\begin{tabular}{|c|c|c|c|c|c|c|c|c|}
\hline \multirow[t]{3}{*}{$\begin{array}{c}\text { Type of } \\
\text { nebuliser }\end{array}$} & \multicolumn{2}{|c|}{$\begin{array}{c}\text { Before } \\
\text { nebulisation }\end{array}$} & \multicolumn{6}{|c|}{ After nebulisation } \\
\hline & & & \multicolumn{2}{|c|}{$\begin{array}{l}\text { Nebuliser } \\
\text { reservoir }\end{array}$} & \multicolumn{2}{|c|}{$\begin{array}{c}\text { Upper stage of } \\
\text { FSI }\end{array}$} & \multicolumn{2}{|c|}{$\begin{array}{c}\text { Lower stage of } \\
\text { FSI }\end{array}$} \\
\hline & $\begin{array}{l}\text { Z-ave } \\
(\mathrm{nm})\end{array}$ & PDI & $\begin{array}{l}\text { Z-ave } \\
(\mathrm{nm})\end{array}$ & PDI & $\begin{array}{l}\text { Z-ave } \\
(\mathrm{nm})\end{array}$ & PDI & $\begin{array}{l}\text { Z-ave } \\
(\mathrm{nm})\end{array}$ & PDI \\
\hline Air-jet & $\begin{array}{l}139.3 \pm \\
2.42\end{array}$ & $\begin{array}{l}0.56 \pm \\
0.03\end{array}$ & $\begin{array}{l}363.50 \pm \\
31.05\end{array}$ & $\begin{array}{l}0.75 \\
\pm 0.14\end{array}$ & $\begin{array}{l}258.40 \pm \\
14.4\end{array}$ & $\begin{array}{l}0.83 \pm \\
0.19\end{array}$ & $\begin{array}{l}172.50 \pm \\
18.36\end{array}$ & $\begin{array}{l}0.35 \pm \\
0.08\end{array}$ \\
\hline $\begin{array}{l}\text { Vibrating- } \\
\text { mesh }\end{array}$ & $\begin{array}{l}146.2 \pm \\
4.58\end{array}$ & $\begin{array}{l}0.53 \pm \\
0.01\end{array}$ & $\begin{array}{l}210.90 \\
\pm 22.78\end{array}$ & $\begin{array}{l}0.77 \pm \\
0.10\end{array}$ & $\begin{array}{l}250.00 \pm \\
88.02\end{array}$ & $\begin{array}{l}0.72 \pm \\
0.16\end{array}$ & $\begin{array}{l}112.60 \pm \\
13.51\end{array}$ & $\begin{array}{l}0.37 \pm \\
0.03\end{array}$ \\
\hline
\end{tabular}




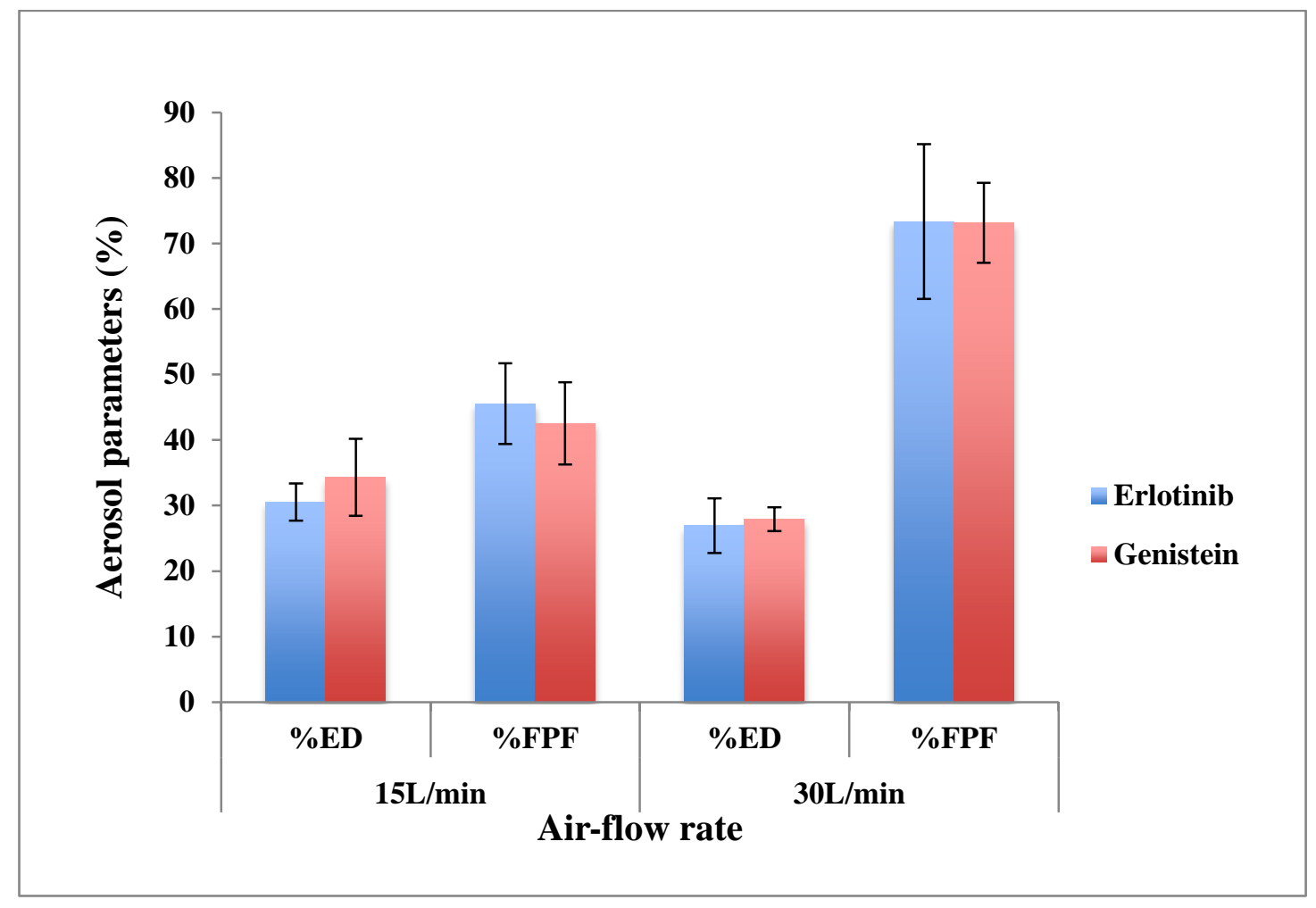

Fig. 1 Aerosol parameters of sonicated co-loaded MLV aerosols generated using air-jet nebulisers using a cooled FSI at 15 and $30 \mathrm{~L} / \mathrm{min}(n=3$, mean \pm S.D. $)$. 


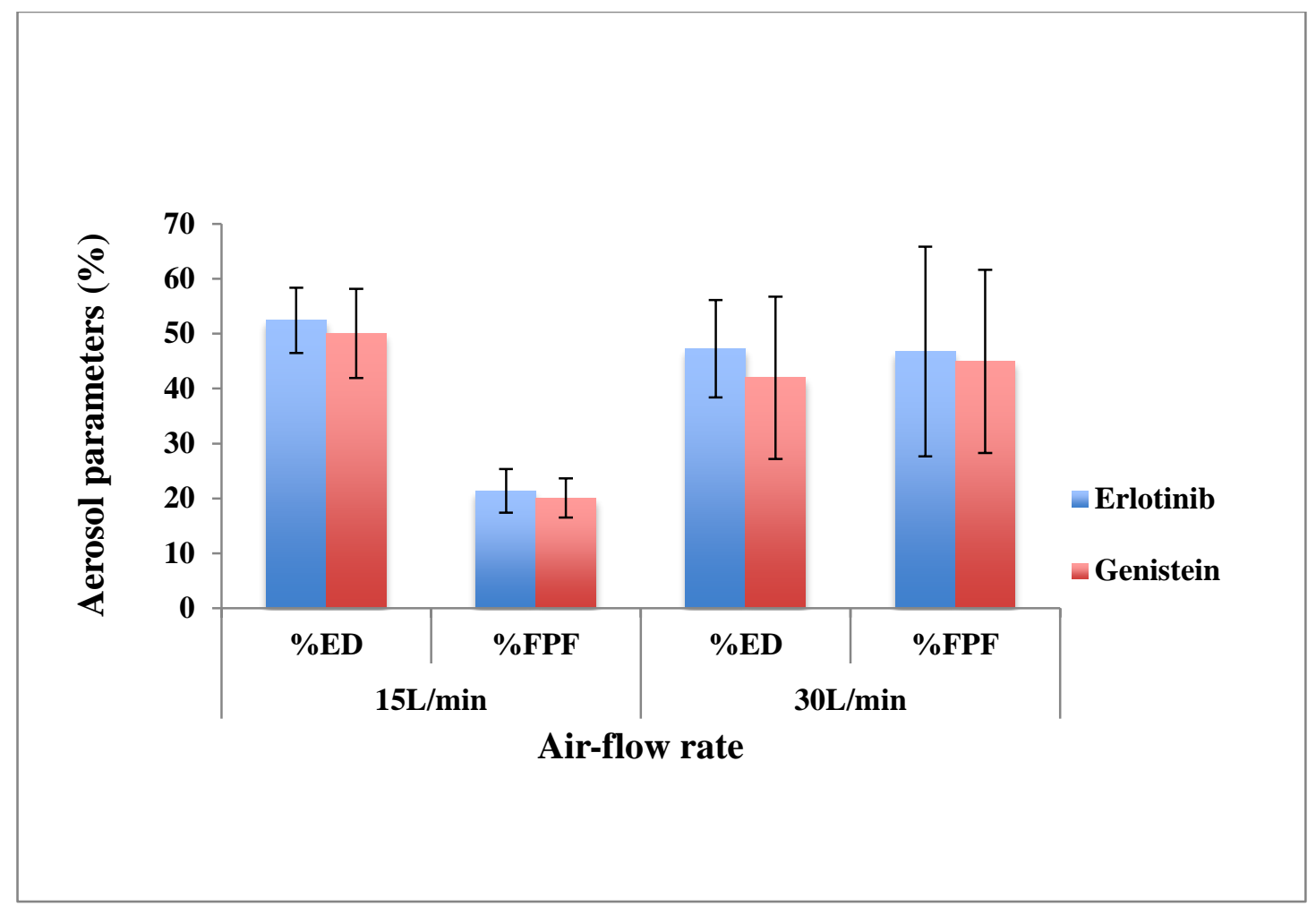

Fig. 2 Aerosol parameters of sonicated co-loaded MLV aerosols generated using vibrating-mesh nebulisers using a cooled FSI at 15 and $30 \mathrm{~L} / \mathrm{min}(\mathrm{n}=3$, mean \pm S.D.). 

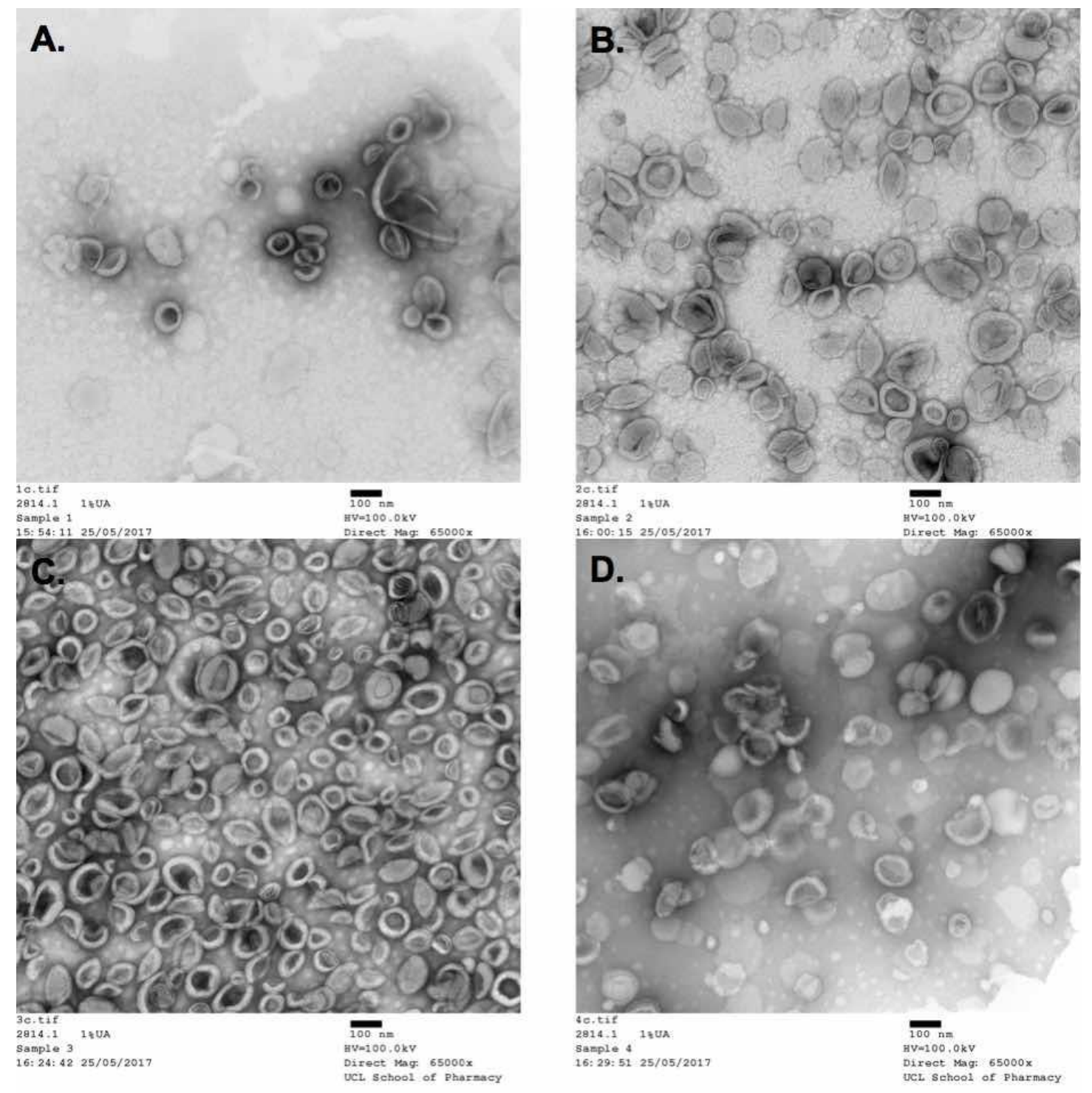

Fig. 3 TEM images of sonicated liposomes before and after air-jet nebulisation. (A.) Freshly prepared sonicated liposomes, (B.) liposomes remaining in nebuliser reservoir, (C.) liposomes deposited on upper stage of the FSI and (D.) liposomes deposited on the lower stage of the FSI 